\title{
A concepção de demanda em saúde mental na Atenção Primária à Saúde
}

\author{
The concept of mental health demand in Primary Health Care
}

\author{
Tamara Alexandra Arias Schutela, Jeferson Rodrigues ${ }^{\mathrm{b}}$, Girlane Mayara Peres ${ }^{c}$ \\ a Assistente social. Especialista em saúde da família modalidade residência, Universidade Federal de Santa Catarina (UFSC). \\ b Enfermeiro. Doutor em enfermagem (UFSC). \\ c Psicóloga. Mestre profissional em saúde mental e atenção psicossocial (UFSC).
}

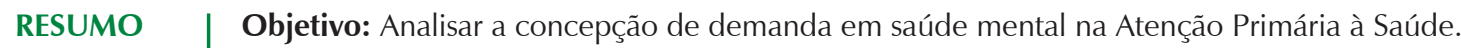

Materiais e Métodos: Dados oriundos de uma revisão integrativa de literatura. A busca foi realizada em quatro bases de dados interdisciplinares, LILACS, Scielo Brasil, Index Psi e BDENF. Foi realizado o cruzamento de 30 descritores relacionados à temática abordada, resultando em 190 artigos dos quais foram selecionados 14 a partir dos critérios de inclusão e exclusão.

Resultados: Os dados foram sistematizados em duas categorias de análise: a) concepção interparadigmática de demanda em saúde mental na Atenção primária à Saúde e b) desafios para respostas às demandas em saúde mental na Atenção Primária à Saúde.

Conclusão: Constatou-se que as concepções de saúde mental na Atenção Básica estão pautadas nos manuais clínicos de inferência biomédica, trazendo à tona a prioridade em rever a concepção de demanda em saúde mental para a consolidação da reforma psiquiátrica e a prática profissional.

Palavras-chave: demanda; saúde mental; Atenção Primária à Saúde.

ABSTRACT I Objective: This paper aims at analyzing the concept of mental health demand in Primary Healthcare.

Materials and Methods: All the information was taken from an integrative literature review as the research was carried out in four interdisciplinary databases, LILACS, SciELO Brazil, INDEXPsi and BDENF. The data crossing was made out of 30 descriptors related to the theme in discussion, resulting in 190 articles of which 14 were selected according to the inclusion and exclusion criteria.

Results: Data were organized into two categories of analysis: a) interparadigmatic conception of mental health demand in Primary Healthcare b) the challenges to respond to the demands in mental health in Primary Healthcare.

Conclusion: It was found that the mental health conceptions in Primary Healthcare are guided in clinical manuals of biomedical inference what indicates the priority to review the concepts of mental health demand for the consolidation of the psychiatric reform and the professional practice.

Keywords: demand; mental health; Primary Healthcare. 


\section{INTRODUÇÃO}

Desde a década de 1990 a atenção à Saúde Mental como estratégia de cuidado tem-se direcionado para o território, a comunidade e com foco na pessoa em sofrimento psíquico, considerando seu contexto social e familiar. Esta característica torna-se possível pelo movimento de Reforma Sanitária e Psiquiátrica no Brasil a partir do reconhecimento da falência do sistema hospitalocêntrico, estritamente medicamentoso e biomédico ${ }^{1}$.

Neste sentido, ao longo dos anos, através de inúmeros movimentos que aconteceram no cenário internacional, a exemplo da Psiquiatria Democrática na Itália e mais recentemente no cenário nacional o Movimento de Luta Antimanicomial, o louco e a loucura sofreram ressignificações, tendo como prioridade um cuidado que se ocupe da pessoa e não mais da doença² .

A reforma psiquiátrica junto a suas dimensões epistemológica, jurídico-política e sócio-cultural, propõe em seu conjunto de prática a implementação de serviços substitutivos com bases territoriais e de atenção psicossocial, para integrar e reabilitar as pessoas em sofrimento psíquico no território e sociedade. Para avançar este pressuposto, no ano de 2011, o Ministério da Saúde (MS) instituiu a Rede de Atenção Psicossocial (RAPS) no âmbito do Sistema Único de Saúde (SUS). Esta estratégia tem como finalidade ampliar e promover o acesso da população, em especial às pessoas com sofrimento ou transtorno mental e com necessidades decorrentes do uso de crack, álcool e outras drogas, através da integração entre os diversos serviços nas regiões de saúde³.

A RAPS como articuladora dos pontos de atenção em saúde mental, integra os serviços através das linhas de cuidado e encontra na Atenção Primária à Saúde (APS) seu componente ordenador. A APS tem como um dos seus objetivos facilitar o acesso ao sistema de saúde, incluindo as situações que necessitem de atenção em Saúde Mental. Considera-se que esse é um espaço privilegiado para estimular os vínculos de compromisso e corresponsabilidade entre usuários, gestores e profissionais de saúde, juntamente com a comunidade, sustentado no conceito ampliado de saúde, intervindo nos fatores de vulnerabilidade e fortalecendo as potencialidades expostas no território ${ }^{4}$.

A APS através da Estratégia de Saúde da Família (ESF) e com o suporte do Núcleo de Apoio à Saúde da Família (NASF) tornou-se um modelo privilegiado de atenção à saúde para a superação do modelo curativo e hospitalocêntrico, na medida em que está mais próxima da população e tem como um dos seus princípios o cuidado longitudinal. O acesso que a APS permite aos usuários abre espaço para o reconhecimento dos aspectos subjetivos e sociais da pessoa em sofrimento psíquico e de sua família, trazendo à cena as singularidades do território em que vive e com quem se relaciona. Dessa forma, a história de cada pessoa é um elemento importante para a constituição do protagonismo no processo de atenção em saúde mental, por isso a contribuição que o campo da saúde mental oferece a APS é fortalecer a integralidade como princípio do SUS ${ }^{5}$. Destarte, a APS está em consonância com os princípios da Reforma Psiquiátrica e torna-se o lócus potencial de atenção a pessoa em sofrimento psíquico.

Entretanto, a APS como porta de entrada recebe uma população com diversos tipos de queixas, problemas, necessidades, desejos e demandas que por vezes uma escuta profissional apressada, ou com frágil orientação teórico crítico-reflexiva ou ainda com um fluxograma de acolhimento indefinido, pode mistificar uma realidade ao ponto de reduzir o sofrimento humano e sua complexidade.

Sabe-se que documentos, normativas, diretrizes entre outros, são demarcações intencionais do contexto sanitário de uma realidade local (gestor e profissionais) que se espera que os trabalhadores executem. Logo, conceitos estruturantes, a exemplo do termo demanda, devem estar esclarecidos, de modo que não sejam naturalizados para guiar a prática clínica.

Diante disso, a exemplo do município de Florianópolis, há o documento referente a Carteira de Serviços que ordena a Atenção Primária em Saúde e "que define normas e diretrizes para o funcionamento das equipes e serviços de atenção primária"6:5. Este documento define que a realização dos atendimentos à população deve acontecer através de demandas espontâneas e programadas, e ainda através de busca ativa por parte das equipes. Além do documento normativo citado, outros documentos do MS e artigos científicos ao aprofundar a temática de saúde mental na APS, trazem corriqueiramente o termo "demanda em saúde mental", porém a qual demanda se referem?

O objetivo deste estudo é analisar a concepção de demanda em saúde mental na Atenção Primária à Saúde através de uma revisão integrativa de literatura. A relevância da proposta deste estudo consiste na contribuição para a reflexão dos trabalhadores da APS sobre o acolhimento e cuidado. Entende-se que nos atendimentos escuta-se a demanda e se intervém com o objetivo de resolver o máximo de problemas no local e de singularizar a relação, superando os tradicionais atendimentos eventuais despersonalizados ${ }^{7}$, ou seja, a desmistificação conceitual de demanda pode qualificar diretamente a integralidade do cuidado. O acolhimento é importante, pois, a APS tem a vantagem de ser menos carregada com os estigmas que cercam os serviços de saúde mental, mas parece que nela os profissionais ignoram isso para reconduzir sempre o usuário (seja de saúde mental 
ou não) ao lugar de doente, ou seja, recriam o dispositivo mais tradicional dentro do serviço que potencialmente pode fazer a diferença.

\section{MATERIAIS E MÉTODOS}

Trata-se de uma revisão integrativa da literatura (RI) referente à concepção de demanda em saúde mental na Atenção Primária à Saúde (APS) sustentada no referencial metodológico de Ganong ${ }^{8}$. O método da revisão integrativa seguiu os passos representados na Figura 1.

A busca pelos artigos e as escolhas dos descritores contou com auxílio de uma bibliotecária da Universidade Federal de Santa Catarina (UFSC). As bases de dados pesquisadas foram Scielo Brasil, BDENF, LILACS e Index Psi. Foram utilizadas trinta palavras chaves para que o escopo de artigos fosse ampliado, são elas: Saúde mental, transtorno mental, transtornos mentais, doença mental, doenças mentais, atenção psicossocial, atenção psicossociais, transtorno psicossocial, transtornos psicossociais, demanda, Atenção Primária à Saúde, Serviços Básico de Saúde, Estratégia Saúde da Família, Atenção Primária, Atenção Básica, atendimento primário, cuidados primários, Centro de Saúde, Centros de Saúde, NASF, PSF, ESF, Unidade básica de saúde, Estratégia da saúde da família, Estratégia de Saúde da Família, Estratégia de Saúde Familiar, Estratégia Saúde Familiar, Programa saúde da Família, Programa de Saúde Familiar, Programa de Saúde da Família.

Com esta combinação agregou-se 190 artigos, distribuídos em 117 na base de dados LILACS, 30 do Scielo Brasil, 23 da Index Psi e 19 do BEDENF. Para a escolha dos artigos a serem pesquisados os critérios de inclusão foram: estarem indexados, nacionais, que respeitassem a particularidade da concepção de demanda em saúde mental na Atenção Primária à Saúde no cenário brasileiro. O período delimitado foi entre os anos de 2001 a 2014 devido a este recorte temporal contemplar o início da Lei $10.216^{9}$, conhecida como a lei da Reforma Psiquiátrica, sancionada no ano de 2001. A partir desta data a saúde mental tem se desenvolvido com mais investimento na APS'.
Foram excluídos os artigos cujo método ou objetivo não estivessem claros, artigos duplicados, teses, dissertações, trabalhos de conclusão de curso, materiais publicados em outros idiomas e estudos que não correspondessem ao escopo delimitado para este artigo.

A partir da aplicação metodológica, este estudo contemplou 14 artigos que se relacionassem com seu objeto. Os artigos selecionados foram lidos na íntegra, e para auxiliar na análise dos dados foi elaborada uma tabela previamente definida que inclúa: a identificação do artigo original, ano de publicação, objetivo da pesquisa, abordagem de demanda em saúde mental, discussões, resultados, conclusões, recomendações, local e participantes.

Para realizar a análise das informações encontradas foi seguido o método de análise de conteúdo proposto por Minayo ${ }^{10}$, que consiste em três etapas: a) pré-exploração do material ou leitura flutuante, nesta etapa separa-se o corpus de análise durante a leitura dos resumos; b) seleção das unidades de análise ou significado, que consiste nos recortes textuais que fazem sentido ao objeto de estudo, neste estudo a "demanda de saúde mental na atenção primária à saúde"; e c) processo de categorização e subcategorização.

\section{RESULTADOS}

Foram analisados os 14 artigos que contemplaram os critérios de inclusão e exclusão, incialmente a partir de uma leitura flutuante e posteriormente uma leitura na integra e mais detalhada.

O principal local de produção dos artigos se concentrou no Nordeste com oito estudos $(57,1 \%)$. Seguido pela região Sudeste com quatro publicações $(28,5 \%)$, os outros dois artigos na região Sul (14,2\%). Referente aos anos de publicações o mais antigo é datado de 2005 e o mais recente publicado em 2014. Em 2012 ficou centralizado o maior número de artigos, perfazendo cinco estudos $(35,7 \%)$, em 2009 foram publicados três artigos $(21,4 \%)$. Os demais foram divididos nos anos 2005, 2010, 2013 e 2014.

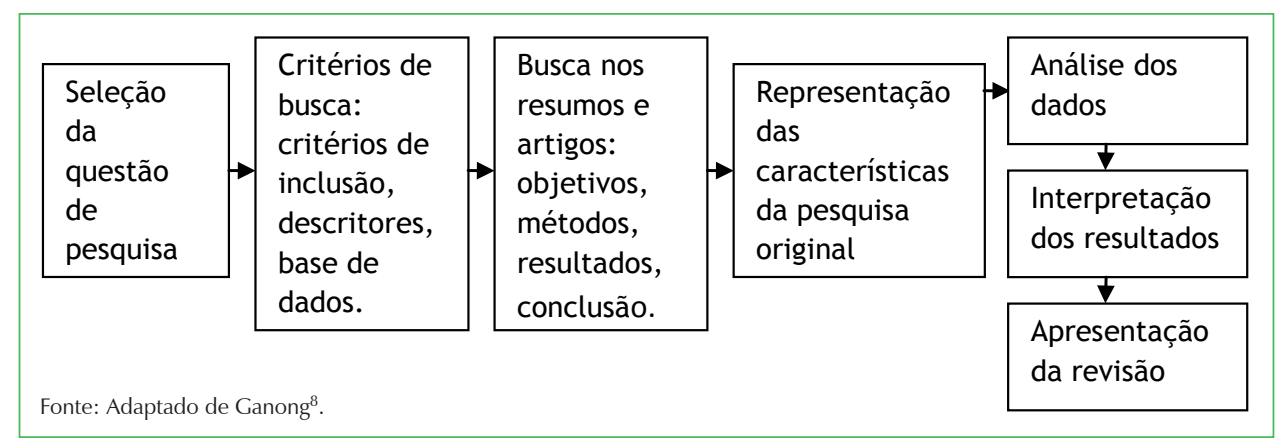

Figura 1. Percurso metodológico utilizado na construçao da revisão integrativa. 
No que se refere ao tipo de estudo, 11 foram pesquisas de campo $(78,6 \%)$ e três estudos bibliográficos (21,4\%). 12 dos 14 artigos selecionados eram de abordagem qualitativa $(85,7 \%)$, um quali-quantitativo e outro quantitativo, demonstrando que a abordagem qualitativa é mais utilizada no que se refere ao presente objeto pesquisado.

A partir dos resultados descritos foi possível apontar duas categorias de análise: a) concepção interparadigmática de demanda em saúde mental na APS e b) desafios para respostas às demandas em saúde mental na APS. Essas categorias sistematizam a discussão e apresentam um panorama geral dos resultados encontrados nos artigos selecionados a respeito da concepção de demanda em saúde mental na Atenção Primária à Saúde no Brasil.

\section{DISCUSSÃO}

A partir da apreciação dos artigos foram construídas duas categorias de análise que melhor sistematizassem a discussão da concepção de demanda em saúde mental na APS. Em um primeiro momento será tratada a concepção interparadigmática de demanda em saúde mental na APS, posteriormente os desafios para as respostas às demandas em saúde mental na APS.

\section{Concepção interparadigmática de demanda em saúde mental na APS}

Ao abordar a concepção de demanda em saúde mental partiu-se do princípio de que não se trata de uma conceituação estática ou inquestionável. Dessa forma, se fez necessário abarcar a complexidade que se apresenta nesta proposta. A complexidade não deve ser compreendida como complicação, mas sim "reporta ao problema ético das relações entre os homens e para com a natureza, porque coloca o problema do pensar e agir em termos de relações e não de objetos"11:33. Neste sentido, considerar uma proposta epistemológica como totalmente suficiente para responder ao questionamento aqui proposto seria desconsiderar que a concepção de demanda em saúde mental na APS é constituída pela relação de elementos distintos (cultural, social, político), porém característico do todo.

Destarte, qualquer tentativa de homogeneização epistemológica pode significar a redução da "complexidade dos fenômenos ao que pode ser abordado pelas regras do discurso de um campo de saber que se pressupõe central, ou de um único paradigma dentro de um mesmo campo de

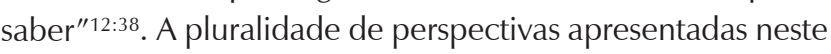
estudo evidencia o dinamismo e o movimento político, social e cultural que a permeiam.

Demanda é ação de demandar, ato de buscar, procurar, também pode ser compreendido como pedir ${ }^{13}$. Nos artigos pesquisados, observou-se que o termo demanda tem sido utilizado de forma corriqueira na APS, pois é ausente uma reflexão epistemológica e teórico-crítica sobre o processo histórico da forma como a ciência se utiliza de sua apropriação teórico-prática. Significa que a compreensão do termo demanda fica restrita ao senso comum de queixa de forma acrítica. Esta observação também é válida para os documentos oficiais do Ministério da Saúde, a exemplo do Caderno de Atenção Básica no 34 - Saúde Mental ${ }^{5}$, que afirma apresentar e discutir "as principais demandas em saúde mental", sem assinalar uma concepção teórico-metodológica de demanda.

Em uma perspectiva crítico-reflexiva, a Psicanálise Freudiana faz a distinção de necessidade e demanda, onde a primeira tem sempre um objeto que a satisfaz, como o alimento atende a necessidade da fome. Na segunda há sempre um pedido de restituição de um estado anterior que o sujeito supõe existir ou ter existido. Antes de tudo a demanda é formulada e endereçada ao Outro ${ }^{14}$. A demanda não visa a um objeto e sim ao Outro a quem se dirige a fala, pois a "demanda está para além e para aquém de si mesma, que, ao se articular com o significante, ela demanda sempre outra coisa (...) o que quer dizer a demanda para além do que ela formula"15:353.

A Análise Institucional se aproxima da concepção de demanda instituída pela psicanálise, quando afirma que "o usuário demanda isso, mas não sabe que, na verdade, demanda outra coisa" 16:94. Entretanto, este mesmo autor vai além ao descrever que "não existe demanda espontânea e natural, nem universal, nem eterna, pelo contrário, ela é produzida pela oferta"16:94, ou seja, existe algo anterior à demanda: a oferta.

A demanda não existe por si. Quando alguns psicanalistas falam hoje em análise da demanda como a expressão do desejo, eles não têm aparelho teórico para pensar que o processo não começa aí, que essa demanda de análise foi produzida pela oferta prévia da análise ${ }^{16: 60}$.

Ao verificar como a concepção de demanda em saúde mental na APS apareceu nos artigos aqui estudados, é notória que elas foram descritas, principalmente, pelas categorias nosográficas e de diagnóstico psiquiátrico, expressos nos seguintes trechos:

... há evidências de alta prevalência de demanda em saúde mental na atenção primária no Brasil dentre a população atendida, caracterizada em grande parte por casos de quadros depressivos e ansioso-leves ${ }^{17: 166}$. 
As demandas médico-sociais identificadas nos grupos focais como sendo as mais frequentes nas comunidades atendidas foram relacionadas ao uso de drogas ilícitas, violência doméstica, alcoolismo e a depressão ${ }^{18: 887}$.

Demanda de saúde mental não tem no SIAB, é uma coisa que a gente desde começo questionava porque realmente tem aparecido muita gente. É uma doença que tem aumentado absurdamente, sobretudo em se tratando de depressão, mas a gente não tem onde colocar isso no SIAB ${ }^{19: 854}$.

A partir da concepção de demanda de Baremblitt ${ }^{16}$ e das principais demandas em saúde mental na APS que foram citadas nos artigos aqui estudados, é necessário compreender a epistemologia das nosografias psiquiátricas, ou seja, abranger o que há anterior a demanda: a oferta criada.

Desde a antiguidade busca-se agrupar as enfermidades humanas, a nosografia (nosos: doenças; graphein: descrição) e a nosologia (nosos: doença; logo: ciência) tratam da classificação e definição das diversas características das doenças. Distintos congressos e conferências discutiram a nosografia a nosologia e, em 1900, se conveniou a Classificação Internacional de Doenças (CID-I), mantida pela Organização Mundial de Saúde (OMS). Desde então, a CID vem sendo revista periodicamente, atualmente estando em sua $10^{\mathrm{a}}$ revisão ${ }^{20}$.

Em saúde mental, ainda sobrepujada pelo saber médico psiquiátrico, se tem, desde 1952, o Diagnóstico e Estatística das Perturbações Mentais - DSM, recentemente em sua 5a revisão. Os diagnósticos em psiquiatria sofrem diversas mudanças, o que é considerado normal numa determinada época pode ser considerado patológico em outra, exemplo disso é a homossexualidade considerada patológica até 1994. Cada edição reflete o contexto político, social e cultural da época do seu lançamento ${ }^{21}$.

Dessa forma, as concepções de demanda em saúde mental apresentadas nos artigos estudados foram influenciadas pelo paradigma biomédico através da classificação dos diagnósticos psiquiátricos e, ao longo dos anos, esta concepção sofreu influências estruturais conforme o contexto social do período.

Agentes de saúde (...) forneceram respostas heterogêneas sobre transtornos mentais, com raciocínios frequentemente restritos ao aspecto biológico. As práticas relatadas foram caracterizadas por distanciamento cognitivo, afetivo e físico. O isolamento social, característica comum em transtornos mentais, foi interpretado unicamente como decorrência de fatores individuais e não sociais ${ }^{22: 1027}$.
As demandas foram descritas pelas unidades, seguindo a terminologia diagnóstica médico-psiquiátrica, utilizando-se das categorias nosográficas presentes no DSM IV. Algumas vezes as demandas foram descritas por meio de sintomas, ou falas que denotavam a existência de sofrimento psíquico ${ }^{23: 21}$.

O fato de os sintomas apresentados pelos usuários com transtornos mentais comuns nem sempre se adequarem perfeitamente às bases categóricas dos diagnósticos psiquiátricos pode levar ao não reconhecimento do transtorno por parte dos profissionais, que em geral enfocam a queixa somática imediata ${ }^{24: 39}$.

É importante salientar que não existe a intenção de minimizar o saber biomédico, e sim ressaltar que as demandas atuais são também produtos de uma sociedade associada ao seu modelo de produção, no Brasil, o capitalismo. A relação entre o Estado, Mercado e Sociedade é permeada pela luta de classes, logo, entende-se que os interesses da produção e do lucro a priori, que no campo da saúde é observado pelo complexo médico financeiro, é mais valorizada em detrimento a subjetividade humana e bem estar do sujeito em sofrimento psíquico. Assim sendo, esse sujeito não se reconhece na sua demanda, pois não é uma construção dialética, onde o sujeito demandante participa da produção da sua demanda, mas sim, unilateral e verticalizada, pois "as pessoas estão solicitando uma coisa, mas o que elas querem obter é outra"16:98. Este contexto ideológico se reproduz nas relações sociais e salienta-se que a crítica e o questionamento a demanda pelo profissional deve ser realizada também sob a estrutura social.

Compreende-se que as demandas expressas nos artigos analisados são previamente determinadas e influenciadas pelas ofertas predominantes em saúde mental, a que seja os diagnósticos médico-psiquiátricos e as variáveis de tratamentos, tal como a busca pelo especialista, os pedidos e encaminhamentos para internações e principalmente o uso de medicamentos. Cabe, portanto, ao profissional o reconhecimento que o sujeito demanda para além ou aquém do pedido verbalizado.

Ainda é necessário atentar ao termo "transtorno mental", recorrente nos artigos como sinônimo de demanda em saúde mental, que produz a dicotomia entre os transtornos físicos e mentais, também corroborado pela classificação dos manuais, já que estes se apresentam de forma isolada e fragmentada. Segundo Baremblitt, "a realidade com que trabalhamos vem toda junta"16:95, as divisões em especialidade só existem dentro da estrutura atual das equipes, mas não para a demanda do usuário.

São comuns nos estudos encontrados os autores apontarem que os profissionais das unidades de saúde fazem a dicotomia entre generalista e especialista, fragmentando a 
integralidade em saúde, reforçando a dissociação entre os transtornos mentais e físicos. Isso fica expresso nos trechos dos artigos analisados:

Nas ESFS pesquisadas isso se reflete de duas maneiras: o encaminhamento da demanda em saúde mental aos serviços/profissionais especializados e a prescrição de receitas psiquiátricas. As médicas do posto geralmente encaminham para um especialista, porque elas não podem ficar prescrevendo esses medicamentos, né? Então, tem que realmente encaminhar para um especialista ${ }^{25: 68}$.

Eu vim porque o doutor do posto disse que não podia me atender lá, não sabe, que não era o tipo de trabalho dele o meu caso. Nem os remédios eles queriam me dar lá, sabe? Ele me deu um papel e me mandou pra cá. (usuário) ${ }^{26: 67}$.

A APS é um cenário privilegiado no acolhimento de demandas em saúde mental, uma vez que visa compreender e atuar com o conceito ampliado de saúde, onde fatores econômicos, políticos, culturais e as expressões da questão social se relacionam no processo saúde/doença.

A finalidade do Programa Saúde da Família é o acompanhamento da clientela, dentro do seu contexto sócio-cultural, de forma a aproximar a família, a comunidade e os profissionais, com vistas principalmente à promoção da saúde para a melhoria da qualidade de vida da populaçãa $27: 593$.

Podendo assim, evitar práticas de intervenções que levem a psiquiatrização, a fragmentação dos atendimentos, a medicalização social, a culpabilização do sujeito e as internações desnecessárias, contribuindo para a consolidação da reforma psiquiátrica, como afirma Dimenstein et al. ${ }^{28: 24}$ "a identificação e o acompanhamento dessas situações, incorporados às atividades que as equipes de atenção básica desenvolvem são passos fundamentais para a superação do modelo psiquiátrico medicalizante".

Portanto, a concepção de demanda em saúde mental na APS é mais ampla e significativa do que apenas classificações diagnósticas ou pontuais expressões da questão social, ela é, também, produto da miséria e exploração impostas à maioria da população, das políticas públicas inadequadas, das relações de produção capitalista e do próprio paradigma biomédico que influencia a prática dos profissionais cotidianamente das experiências humanas sob sua prática.

Desta forma, para a compreensão da concepção de demanda em saúde mental na APS é necessário à leitura e apropriação das forças antagônicas em jogo no espaço socioeconômico e cultural em que o sujeito está inserido. Para traduzir a concepção de demanda advinda de um pedido ou queixa é necessário reconhecer além da influência da oferta que é anterior à demanda ${ }^{16}$, também é necessária a reflexão acerca daquilo que o sujeito busca como restituição de um estado anterior e para quem ele endereça sua demanda ${ }^{14}$.

\section{Os desafios para as respostas às demandas em saúde mental na APS}

Entende-se que a partir do princípio de que a concepção de demanda em saúde mental na APS é mais ampla e abrangente do que um conjunto de sintomas descritos pelos usuários e classificados pelo paradigma biomédico é preciso refletir a respeito das respostas dadas a esta demanda, uma vez que essas respostas são diretamente proporcionais ao que se compreende da concepção de demanda para o campo da saúde mental.

Nesse sentido, a análise do material coletado indica que as respostas dadas as demandas abordadas nos estudos foram consoantes com a concepção restrita de demanda. Uma vez que prevaleceram nos estudos os excessos de prescrição farmacológica, encaminhamentos para internação psiquiátrica e a busca pelo especialista, em geral o psiquiatra, como as principais intervenções dos profissionais, conforme trechos a seguir:

Contudo, observamos, a partir das narrativas dos trabalhadores entrevistados, que eles não se sentem preparados para o cuidado com essa demanda (...) o que o corre é um encaminhamento para o psiquiatra da Unidade Integrada de Saúde e as equipes ficam apenas renovando as receitas ${ }^{29: 810}$.

É possível observar que a medicalização dos sintomas ainda é uma prática comum na ESF, aonde as constantes renovações de receitas vêm denunciar a tentativa de tornar "médico" aquilo que é da ordem do afetivo, do existencial. Busca-se responder às situações do cotidiano, sofrimentos, desamparo, questões sociais, políticas e econômicas, de forma a enquadrá-la em alguma patologia ${ }^{30: 58}$.

Serviços de atendimento à saúde mental, têm como finalidade resolver crises vitais e remover sintomas agudos em quadros de transtornos mentais, propiciando melhor adaptação do individuo à sociedade e ao trabalho, bem como dando apoio para o melhor enfrentamento das situações desadaptativas. Da mesma forma, intervenções farmacológicas devem ser consideradas em casos de maior severidade e de maior complexidade ${ }^{31: 196}$.

A dispensação de medicamentos psicotrópicos e o consequente controle requerido para tal atividade constituem o principal registro de atuação na área psiquiátrica da ESF. Acrescentam-se os registros de referência e contrarreferência para unidades especializadas e hospitalares ${ }^{32: 658}$. 
Afirma-se que existe uma transformação da demanda a partir da oferta, ou seja, a oferta delineia a demanda porque o profissional não consegue escutar outra coisa senão aquilo que está colocado como possível para o atendimento. Assim, o primeiro desafio constitui no ato de complexificar a concepção de demanda em saúde mental. O sujeito em sofrimento psíquico ao adentrar uma porta de um serviço da APS ele acaba por se institucionalizar, ou seja, sua subjetividade é cooptada através de protocolos inflexíveis e procedimentos rígidos que normatizam as formas de lidar, olhar e sentir a pessoa em seu sofrimento. Passa a lidar com o objeto doença e não mais com a pessoa. Isso expressa que há uma simplificação da demanda que é por si complexa, pois se trata do ser humano com sua subjetividade.

Dessa forma, o profissional necessitará se questionar e se implicar com sua própria concepção de demanda, pois para Amarante ${ }^{11} \mathrm{o}$ conhecimento deve ser estendido quanto a seu marco teórico, à filosofia, ao saber complexo e transcendental, ao conhecimento sobre a alma, as paixões, a moral e a cultura, este arcabouço de saberes amplia as respostas ao sujeito em sofrimento psíquico. Aqui expressa o segundo desafio, onde para se responder a complexa demanda do usuário, o profissional precisará reconhecer sua própria demanda seja de conhecimento, aperfeiçoamento, tempo, dedicação, relação de forças institucionais, entre outros.

Assim, para que o profissional responda as demandas em saúde mental, Basaglia orienta que a princípio se deve colocar "entre parênteses" a doença e as suas classificações para compreender a pessoa na "modalidades humanas"33:309-10. Amarante ${ }^{11}$ afirma que o princípio de colocar a doença entre parênteses é reconhecer a singularidade da pessoa doente, ou seja, não se ocupar da doença como o saber psiquiátrico determina, mas sim atentar-se aos aspectos que se construiu ao redor dela, colocar vistas para o sujeito e não para o conjunto de sintomas e diagnósticos. As queixas e sintomas relatados pelo usuário ao profissional expressam o real vivido pela ótica do sujeito, e podem ser denominadas de necessidades. Entretanto, a concepção de demanda está no campo do simbólico, ou seja, aquilo que não é dito, mas expresso através de símbolos e representações, para além do que é verbalizado.

Para buscar uma nova resposta ao conceito ampliado de demanda em saúde mental na APS é preciso que os profissionais estejam atentos para além das queixas ou necessidades expostas no momento do acolhimento e cuidado deste sujeito. Que os sintomas, diagnósticos e medicações não sejam mais importantes que a história, que o discurso, que o desejo e as vontades da pessoa em sofrimento. É fundamental a escuta qualificada, ou seja: valorizar sua fala, seu silêncio, gestos, olhares e o que mais vier permear o momento de acolhimento, contextualizado com seu meio cultural, econômico, político e social, para dar respostas criativas e adequadas a cada sujeito, buscando o bem estar, a inserção social e principalmente o direito a saúde. Para Rodrigues e Brognoli ${ }^{34}$ esta forma de acolhimento permite a formulação de um diagnóstico situacional, evitando as classificações dos sintomas e diagnósticos nos padrões CID 10 e/ou DSM.

O terceiro desafio está na compreensão por parte do profissional que seu processo de trabalho é regido pela lógica produtivista, da quantificação e coisificação, o que contribui para a concepção reducionista da demanda em saúde mental. Isso se confirma na produção por números de atendimentos, condições inadequadas da estrutura física ou a falta delas nos centros de saúde, nos baixos salários pagos aos profissionais de saúde. A simples compreensão da lógica em que estão inseridos não é capaz de vencer esse desafio, é preciso buscar a emancipação profissional, articulação com as demais categorias e mobilização social contra a precarização do sistema de saúde público. Vencer a inércia da reprodução para a construção e produção de um sistema de saúde universal, integral e equânime.

Assim sendo, constatou-se que a concepção de demanda em saúde mental na APS é mais ampla e complexa do que as queixas e conjuntos de sintomas verbalizados nos acolhimentos em saúde, ela é uma construção psicossocial do sujeito com seus interlocutores, permeada de subjetividade e diretamente influenciada pela estrutura do contexto na qual está inserida. Para ampliar o olhar e compreender a demanda para além da queixa não existe uma configuração cartesiana que indique a direção. É preciso buscar formas críticas e substitutivas ao senso comum, aos manuais de modelo biomédico e ao niilismo atual. O desafio é conviver com as respostas parciais e inacabadas, suportar lacunas, porém na aposta de que serão construídas respostas na medida em que forem surgindo novas perguntas.

Com isso, para operar transformação a respeito da concepção de demanda em saúde mental, inicialmente, é necessário que o profissional reconheça o seu desejo de alterar o status quo, o que implica uma função subjetiva, ou seja, pulsar por um processo de desalienação do profissional de saúde e, posteriormente, enfrentar os desafios relatados neste artigo através dos saberes já acumulados (psicanálise, antropologia, filosofia, sociologia, política) e aos ainda por serem desenvolvidos.

Portanto, destaca-se que para uma Reforma Psiquiátrica efetiva não basta modificar o espaço físico de atendimento do sujeito se não alterar as concepções que permeiam este meio, transformar o reducionismo, os preconceitos, investir 
em conhecimento e autonomia profissional são partes sine qua non desse movimento. É preciso transformar espaços de governo na medida em que os profissionais exerçam a dimensão ética e política. Caso as transformações não alcançarem também os profissionais, usuários e sociedade corre-se o risco de manter o velho com novas roupagens.

Entende-se que a contribuição à comunidade acadêmica no campo da saúde mental e saúde coletiva, com este estudo, consiste em apontar que as produções pesquisadas indicam uma linearidade paradigmática sobre o termo demanda. Esta investigação possui significado na medida que pode provocar a prática profissional ao interrogar um termo amplamente divulgado e ao mesmo tempo simplificado. Os limites deste estudo abrangem uma realidade estudada, qual seja, produções científicas no Brasil e em um determinado momento específico. Recomendase que mais estudos possam ser realizados na relação demanda e integralidade em saúde na perspectiva da complexidade.

\section{REFERÊNCIAS}

1. Porto KF. Elementos para uma política de avaliação das ações de saúde mental na atenção primária: contribuições de uma pesquisa qualitativa avaliativa [dissertação]. Campinas: Universidade Estadual de Campinas Departamento de Saúde Coletiva; 2012.

2. Amarante PD, Diaz FS. Os movimentos sociais na Reforma Psiquiátrica. Cad Bras Saúde Mental 2012;4(8):83-95.

3. Ministério da Saúde (BR). Portaria no 3.088 , de 23 de dezembro de 2011 que institui a Rede de Atenção Psicossocial. Brasília (DF): Ministério da Saúde; 2011.

4. Ministério da Saúde (BR). Secretaria de Atenção à Saúde. Departamento de Atenção Básica. Política Nacional de Atenção Básica. Brasília (DF): Ministério da Saúde; 2012.

5. Ministério da Saúde (BR). Secretaria de Atenção à Saúde. Caderno de Atenção Básica, no 34 - Saúde Mental. Brasília (DF): Ministério da Saúde; 2013.

6. Florianópolis. Secretária Municipal de Saúde. Carteira de serviços da atenção primária à saúde. Florianópolis: Secretária Municipal de Saúde; 2014.

7. Lancetti A. Saúde mental nas entranhas da metrópole. In: Lancetti A, organizador. Saúde e loucura: saúde mental e saúde da família. 3a ed. São Paulo: Hucitec; 2013. p. 11-52.

8. Ganong LH. Integrative review of nursing research. Rev Nursing Health 1987;10(1):1-11. http://dx.doi.org/10.1002/nur.4770100103

9. Brasil. Lei no 10.216, de 6 de abril de 2001: dispõe sobre a proteção e os direitos das pessoas portadoras de transtornos mentais e redireciona o modelo assistencial em saúde mental. Brasília, DF.

10. Minayo MCS. O desafio do conhecimento: pesquisa qualitativa em saúde. 9aㅡ ed. São Paulo: Abrasco; 2007.

11. Amarante P. O homem e a serpente outras histórias para a loucura e a psiquiatria. Rio de Janeiro: FIOCRUZ; 1996. http://dx.doi. org/10.7476/9788575413272
12. Vasconcelos EM. Complexidade e pesquisa interdisciplinar epistemologia e metodologia operativa. Petrópolis: Vozes; 2002.

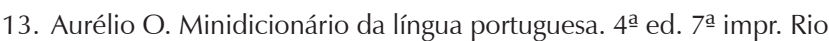
de Janeiro: Aurélio; 2012.

14. Quinet A. A descoberta do inconsciente: do desejo ao sintoma. 4르 ed. Rio de Janeiro: Jorge Zahar; 2011.

15. Lacan J. O Seminário livro 7 a ética da psicanálise. Rio de Janeiro: Jorge Zahar; 1988

16. Baremblitt G. Compêndio de análise institucional. 3aa ed. Rio de Janeiro: Rosa dos Tempos; 1996.

17. Martins AKL, Braga VAB, Souza AMA. Prática em saúde mental na Estratégia Saúde da Família: um estudo bibliográfico. Rev Rene 2009;10(4):165-72.

18. Kanno NP, Bellodi PL, Tess BH. Profissionais da Estratégia Saúde da Família diante de demandas médico-sociais: dificuldades e estratégias de enfrentamento. Rev Saúde Soc 2012;21(4):884-94. http://dx.doi.org/10.1590/s0104-12902012000400008

19. Souza J, Luis MV. Demandas de saúde mental: percepção de enfermeiros de equipes de saúde da família. Acta Paul Enferm 2012;25(6):852-8. http://dx.doi.org/10.1590/S010321002012000600005

20. Vaschetto E. Epistemologia Y Psiquiatria: relaciones peligrosas. Bueno Aires: Polemos; 2012.

21. Burkle TS. Uma reflexão crítica sobre as edições do Manual de Diagnóstico e Estatística das Perturbações Mentais - DSM [dissertação]. Rio de Janeiro: UFRJ; 2009.

22. Souza LGS, Menandro MCS, Couto LLM, Schimith PB, Lima RP. Saúde mental na Estratégia Saúde da Família: revisão da literatura brasileira. Rev Saúde Soc 2012;12(4):1022-34. http://dx.doi.org/ 10.1590/s0104-12902012000400019

23. Baroni DPM, Fontana LM. Ações em saúde na atenção primária no município de Florianópolis, Santa Catarina. Rev Mental 2009; VII(12):15-37.

24. Tavares LB, Souza AR, Pontes RJS. Estudo da demanda de saúde mental em centros de saúde da Família em Caucaia, Ceará, Brasil. RBMFC 2013;8(26):35-42. http://dx.doi.org/10.5712/ rbmfc8(26)492

25. Dimenstein $M$, Severo AK, Brito $M$, Pimenta AL, Medeiros $V$, Bezerra E. O Apoio Matricial em Unidades de saúde da família: experimentando inovações em saúde mental. Rev Saúde Soc 2009; 18(1):63-74

26. Bezerra IC, Jorge MSB, Gondim APS, Lima, LL, Vasconcelos MGF. "Fui lá no posto e o doutor me mandou foi pra cá": processo de medicamentalização e (des)caminhos para o cuidado em saúde mental na Atenção Primária. Interface 2014;18(48):61-74. http:// dx.doi.org/10.1590/1807-57622013.0650

27. Soares TC. "A vida é mais forte do que as teorias" O psicólogo nos serviços de Atenção Primária à Saúde. Psicol Ciênc 2005;25(4): 590-601. http://dx.doi.org/10.1590/S1414-98932005000400008

28. Dimenstein M, Severo AK, Brito M, Santos YF, Morais, C. Demanda em saúde mental em Unidades de Saúde da Família. Rev Mental 2005; III:33-42.

29. Camuri D, Dimenstein M. Processos de Trabalho em Saúde: práticas de cuidado em saúde mental na Estratégia Saúde da Família. Rev 
Saúde Soc 2010;19(4):803-13. http://dx.doi.org/10.1590/s010412902010000400008

30. Barros SCM, Dimenstein M. O apoio institucional como dispositivo de reordenamento dos processos de trabalho na atenção básica. Estud Pesqui Psicol 2010;10(1):48-67. http://dx.doi.org/10.12957/ epp. 2010.9017

31. Molina MRAL, Wiener CD, Branco JC, Jansen K, Souza LDM, Tomasi E, Silva RA, Pinheiro RT. Prevalência de depressão em usuários de unidades de atenção primária. Rev Psiquiatr Clín 2012:39(6): 194-7. http://dx.doi.org/10.1590/S0101-60832012000600003
32. Pinto AGA, Jorge MSB, Vasconcelos MGF, Sampaio JJC, Lima GP, Bastos VC, Sampaio HA de C. Apoio matricial como dispositivo do cuidado em saúde mental na atenção primária: olhares múltiplos e dispositivos para resolubilidade. Rev Ciência Saúde Colet 2012;17(3):653-60. http://dx.doi.org/10.1590/S141381232012000300011

33. Basaglia FO, organizador. Dalla psichiatria fenomenológica all'esperienza di Goriza. Torino: Einaud; 1981.

34. Rodrigues J, Brognoli FF. Acolhimento no serviço de atenção psicossocial. Cad Bras Saúde Mental 2014;6(13):61-74. 